\title{
On-stream floodplain storage: experimental research
}

\author{
G. De Martino, F. De Paola, G. Marini \& A. Ranucci \\ University of Naples Federico II, \\ Department of Hydraulic and Environmental Engineering G. Ippolito, \\ Italy
}

\begin{abstract}
In order to achieve a reduction of flood wave peak discharge in a stream plain zone, it is often possible to take advantage of structural active measures consisting of flood plain storage which can be on-stream or off-stream, whose task is the temporary storage of water flood volumes with the consequent outflow of a discharge that is compatible with the hydraulic characteristic of a stream. For preliminary sizing of these measures, the hypothesis of uniform storage is made, and it is also possible to show it in the technical literature. In order to verify the reliability of the simplified hypothesis of uniform storage, in the Laboratory of the Department of Hydraulic and Environmental Engineering G. Ippolito of the University of Naples Federico II, the experimental prototype of on-stream floodplain storage has been installed and the tests have been carried out, by using a suitable electrical level probe in the inflow and outflow hydrograph reconstruction. The tests, managed by both varying the dimension of the free bottom outlet of the floodplain storage and its surface, have confirmed the reliability of the uniform storage hypothesis. Tests in the presence of obstacles, made of synthetic grass, on the bottom of the floodplain zone, are in progress to simulate the presence of vegetation, and therefore the possible influence of hydraulic resistances on the reliability still of the uniform storage hypothesis.
\end{abstract}

Keywords: hydraulic risk mitigation, structural measures, floodplain storage. 


\section{Introduction}

The floodplain storage represents a structural active measure for the reduction of the flood wave peak discharge $[1,10,16]$. The storage and drainage phenomena of these infrastructures are of two-dimensional type and are, moreover, influenced by a lot of momentum exchanges that take place between the current in the main river bed and that in the expansion areas, as well as by the presence of possible obstacles and unevenness that induce localized resistances to the motion [21].

For a first hydraulic sizing of the floodplain storage, the uniform storage hypothesis is generally adopted, taking into account that the water surface maintains itself horizontal and parallel to the bottom [21, 17], without, therefore, considering the two-dimensional model.

Such an assumption allows one to define a procedure of hydraulic sizing of the floodplain storage, based on the hypothesis of establishing in advance the hydrograph that try the storage $[2,8,12,18,20,22]$, and also on the use of a transformation inflows-outflows model for the definition of the critical rain duration. If the water level maintains itself horizontally during the filling of the floodplain storage it allows a meaningful simplification of the calculations, with the possibility to define sizing nomographs for a quick preliminary evaluation of the volume to assign for a fixed lamination of the flood.

In a previous work [15], the Authors have reported the first results of test experiences run on a physical prototype of an on-stream floodplain storage with a surface of approximately $8 \mathrm{~m}^{2}$ and subsequently of approximately $30 \mathrm{~m}^{2}$, and it has been observed that, at least for a first dimensioning of the structure, the uniform storage hypothesis can be reliable. In the same job, besides, it was suggested to plan further experiences finalized to the evaluation of possible influence of marked resistances and patchiness on the storage-drainage phenomena.

The possible presence of important resistances to motion and/or patchiness can in fact be present in a real situation because of the floodplain storage are infrastructures that don't have a continuous functioning but these are tried by big water volumes just in a few occasions during their life. This means that we can have longer or shorter periods, but, however, in terms of years, in which the area destined to be invaded by water is the centre of morphologic transformations mainly due to the vegetation growth that can also be of high stem plants.

The tendency of the last years, in fact, [24] is to realize the floodplain storages integrating themselves in the economic and social life of the area in which they are built; the huge areas destined to the flooding can be used for the most of their life for other purposes (cultivation, pasture, free time etc.).

The next experimental research that will be presented in this paper is exactly aimed to verify the reliability of the uniform storage hypothesis in presence of marked obstacles due to the greater dimensions of the flooding surface and to the presence of important resistances. 
The presence of the vegetation involves essentially two problems:

- a difference between the geometric storage volume and the useful volume to be invaded;

- an obstacle to the water outflow that moves in the storage zones.

The effect of the resistances to the motion, in general, when the water speeds are low in the river bed, is negligible, but the effect on the reduction of the geometric volume is no doubt to be taken into account [21]. When the areas to be invaded are affected by the movement of the water in a lengthwise direction to the bottom, the vegetation does offer resistance to the motion that can be evaluated with various procedures $[4-6,21,23]$ that could invalidate the uniform storage hypothesis used in the dimensioning models.

\section{Experimental installation}

The prototype of the on-stream floodplain storage has been realized in the Laboratory of the Department of Hydraulic and Environmental Engineering "G. Ippolito" of the University of the Studies of Naples Federico II, and it is shown in detail in fig. 1.

Such prototypes allow one to reproduce the hydraulic behaviour of an on stream floodplain storage equipped with a support structure made of a floodgate: in such a way the outflow of the flows to the inside of the channel occurs undisturbed until the water level gets almost to the bottom side of the floodgate, while the further increase of the discharge causes a sudden rise of the water surface, with the transition to pouring outflow, that allows the filling of the floodplain storage with contemporary reduction of the flood wave peak discharge.

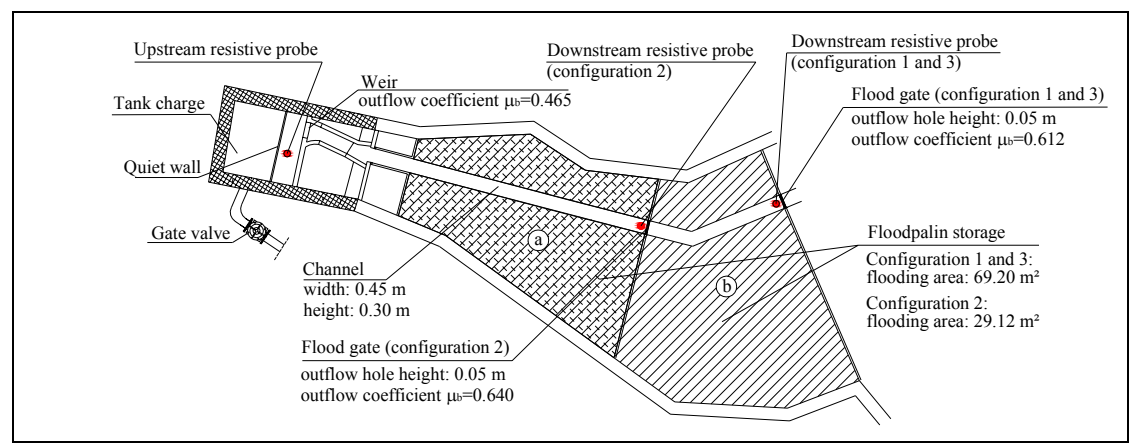

Figure 1: Experimental installation scheme.

The installation (fig. 1) is made of a little charge tank in which the capacity needed for the tests is conveyed by a steel pipe and is regulated by a gate valve; from this tank, through a calibrated weir $\left(\mu_{\mathrm{s}}=0.465\right)$, the water comes in to the channel with rectangular section along which there is the obstruction with a floodgate that leaves a free outflow on the bottom, calibrated as well $\left(\mu_{\mathrm{b}}=0.640\right.$; 0,612 ). The presence of the floodgate induces a pouring of the flows and 
consequently the progressive storage of the water volumes in a properly embanked area. For the water level measurement, two resistive level probes are installed one in the tank charge and another one upstream of the floodgate. Further clarifications about the prototype description can be found in the previous work [15].

\section{Experimental research}

The tests dealt with the reconstruction of incoming and outgoing hydrographs from the storage floodplain, starting from the water levels measured by resistive level probes. The knowledge of the incoming flow to the system has also allowed an estimation of water levels, assuming the uniform storage hypothesis that have been subsequently compared to experimental values.

The proposed numerical model for the estimation of flooding event is based on integration of the differential equation (1):

$$
\frac{d h}{d t}=\frac{1}{S(h)}\left[Q_{i}-\mu_{b} l_{b} \sqrt{2 g(h-s / 2)}\right]
$$

where $S(h)$ is the flooding surface which is a function of water levels $h$ reached in the storage area (uniform storage curve), $l_{b}$ and $s$ are respectively the width and the height of the outflow in correspondence of the gate, $g$ is the gravitational acceleration, $Q_{i}$ is the incoming flow calculated in the prototype by measuring water level up-flow the calibrated weir crest (with outflow coefficient $\mu_{\mathrm{s}}$ ).

The first tests run on such prototype [15] show that the gap between experimentally measured water levels and the ones calculated with the proposed numerical model, based on integration of (1), are modest and therefore the uniform storage hypothesis seems reliable.

The present note refers to the follow up of experimental studies on the same prototype described in paragraph 2 but modified in order to obtain three further configurations aimed to assign, possibly, a greater generality to the conclusions drawn previously:

- configuration 1- The physical prototype is the one of fig. $1 \mathrm{~b}$ essentially characterized by a flooding area $\left(69,20 \mathrm{~m}^{2}\right)$ more than twice the one used in the previous tests;

- configuration 2- The physical prototype is the one of fig.1a with a flooding area of $29.12 \mathrm{~m}^{2}$ covered by synthetic grass to simulate the presence of vegetation on the flooding surface.

- configuration 3- The physical prototype is the one of configuration 1 with the surface covered by synthetic grass.

The configurations are numbered and shown following a logical and not chronological order, in fact: the first configuration is aimed to gain an understanding, in particular, which is the effect on flooding and draining events of the area, the second one, those due to the presence of high roughness and in the third configuration the two effects are concomitants.

Hereafter we report the results about the examined configurations. 


\subsection{Configuration 1 (the effect of the flooded area on the flooding and draining phenomena)}

To verify the possible influence, on the reliability of the uniform storage hypothesis, of the storage surface area on the modalities of flooding, some modifications were applied to the first experimental installation (fig. 1a) in order to increase, by repositioning some boundary banks, the flooding surface (fig.1b).

Also, in this case the tests carried out have shown a good agreement among the experimental values and the ones obtained by numerical integration of (1); for example in figs 2 and 3 the results of one of numerous tests, in terms of hydrographs and water levels upstream of the floodgate, are shown. In the diagram of hydrographs is shown: with continuous line the incoming hydrograph to the storage $\left(\mathrm{Q}_{\mathrm{i}}\right)$, with broken line the outcoming one measured during the tests $\left(\mathrm{Q}_{\mathrm{u}}\right)$ and with dotted line the last one obtained by the numerical model proposed $\left(\mathrm{Q}_{\mathrm{u}, \mathrm{num}}\right)$. In the water levels diagram the comparison is done between measured levels upstream the floodgate $\left(h_{u}\right)$ displayed with continuous line and the calculated with the numerical model one $\left(\mathrm{h}_{\mathrm{u}, \text { num }}\right)$ in broken line.

The phase of filling is important for the sizing of the volume of the storage floodplain; but the emptying one is useless for understanding the flooding and draining events.

The numerical model of uniform storage based on the integration of the (1) represents very well the filling phase of the box, but not the emptying one.

Such a gap between numerical and experimental data in the final phase is to be referred to the increase of the surface plain-highness irregularities of the storage floodplain in comparison to the configuration of Fig. 1a.

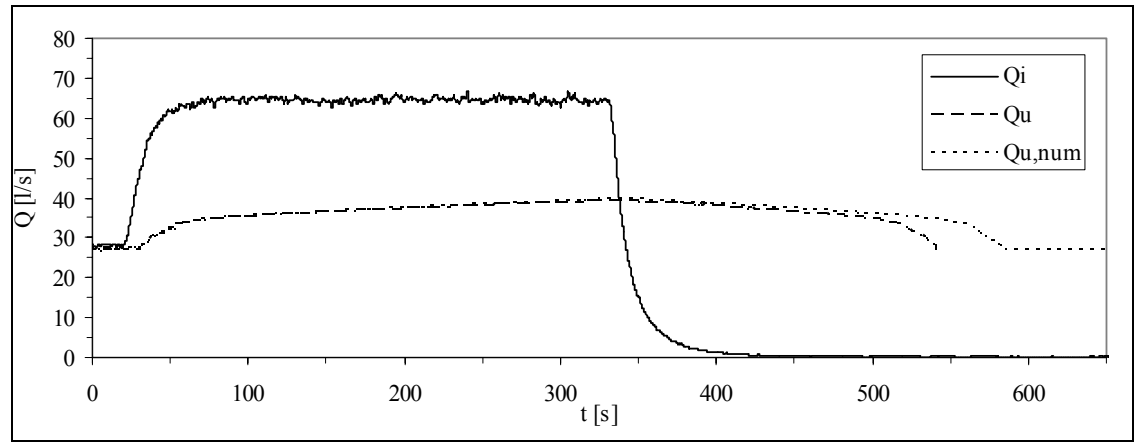

Figure 2: Configuration 1: Incoming and outgoing hydrographs.

Such irregularities imply the formation of "backwater areas": a part of the water in the storage is held back and therefore the volume of water that flows to the prototype's channel is reduced in comparison to the one actually held; this implies a more rapid decrement of the water levels in the channel with the final effect, that does not actually occur, of a more rapid emptying of the storage: in reality the floodplain storage, until the measurements can be acquired, is not completely empty but it keeps a certain amount of water in the "backwater 
areas", that can be estimated with good approximation by the hydrographs integrating the inclusive area between the numerical curve and the experimental one considered in phase of draining.

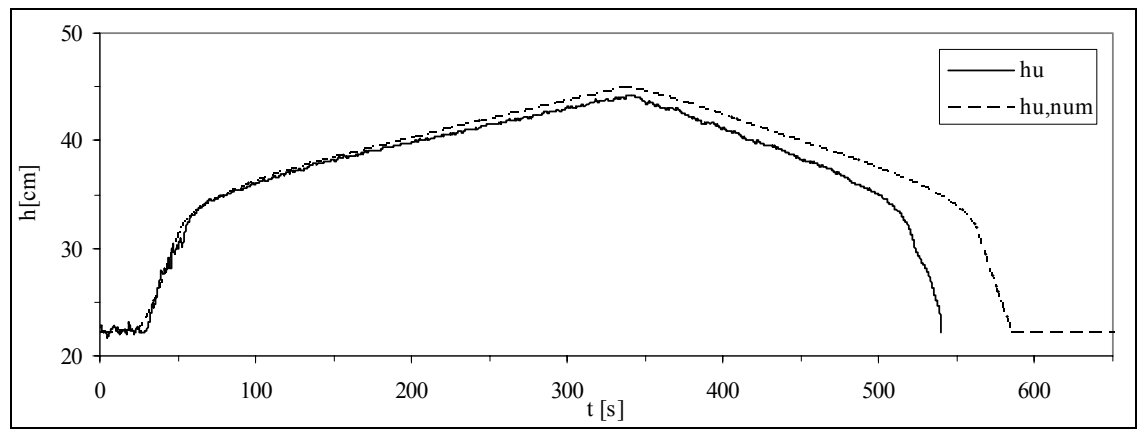

Figure 3: Configuration 1: water levels upstream the floodgate.

\subsection{Configuration 2 (effect of the presence of vegetation on flooding and draining phenomena)}

In order to clarify the hydraulic aspects related to the presence of vegetation, tests have been carried out to estimate the effects of the same one on the modalities of filling the storage, aimed to verify if the hypothesis of uniform storage can be still reliable.

The presence of the vegetation inside of the floodplain storage has been simulated by putting some synthetic grass, characterized by flexible leaves made of $100 \%$ poliolefine, type of fiber B-SOFT, height $55 \mathrm{~mm}$, total height $57 \mathrm{~mm}$, points $/ \mathrm{m}^{2} 11250$, total weight $2665 \mathrm{~g} / \mathrm{m}^{2}$. In fig. 4 an overview of the prototype with covered surface and a detail of the synthetic grass used for the cover is shown.

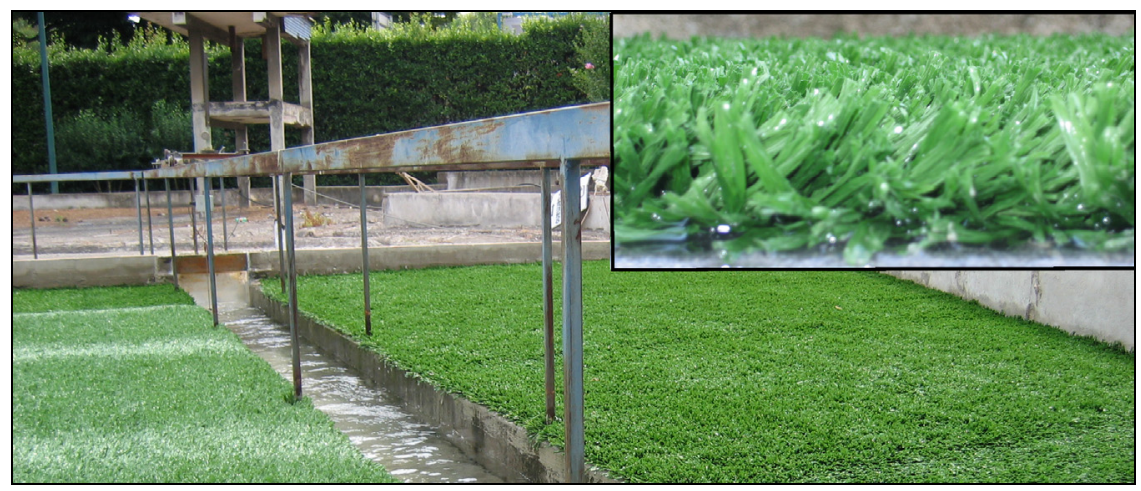

Figure 4: Overview of surface and particular of synthetic grass. 
As an example we report the results only in terms of water course level upstream the floodgate (fig. 5) about one of the many tests carried out.

In the phase of filling, the presence of the vegetation induces a modest increment of water level in the channel in the case of absence of grass; this is due to the need that the water mass has to exceed the obstacle represented by the grass and to fill the storage. This involves a small gap between the experimental curve $\left(h_{u}\right)$ and the numerical one $\left(h_{u, \text { num }}\right)$ obtained by the model that does not consider the presence of the vegetation.

In the phase of draining, the presence of vegetation involves a slower draining because of two concomitant effects:

- the first, and marginal one, is due to the obstacle represented by the presence of the grass to the motion of the water: the measured water level in the channel are reduced with respect to the ones estimated by the numerical method by integrating the (1) that does not considered the presence of the grass; such an event, by itself does not justify the remarkable gap between experimental curve and numerical one;

- the second one is due to the formation of "backwater areas": part of the stored water is held back and therefore the water volume that flows to the channel is reduced with respect to the one actually stored; this implies a quicker decrease of water level in the channel with the final effect, not actually occurring, of a quicker draining of the storage: in reality the storage, until the measurements can be acquired, is not completely empty but it maintains a water part in the "backwater areas". The withheld volume is estimable with good approximation starting from the diagrams of the hydrographs integrating the area included between the numerical curve and the experimental one considered in phase of draining.

The final phase of the draining is interpretable applying the theory of the storage, probably not linear.

In fig. 5 two significant points are shown, found during the tests: first (A), represents the moment in which the water it begins to submerge the grass, second (B) represent the first moment in which all the grass is submerged. The positioning on the curve of water level of these two points allows one to define three flooding phases: the first included between the initial point and the point $\mathrm{A}$; the second one, included between the point $\mathrm{A}$ and the point $\mathrm{B}$, is the starting phase of filling of the storage in which progressively the grass is submerged; the third, that goes from the point B to the beginning of the drain, is the one in which the storage is flooded, with the grass completely submerged.

The increment of water level in time (the gradient of the curve) in the first phase is greater in comparison to the one of following phases because the surface of the channel is much lower than that one of the storage; the two following phases have a gradient much similar, and this allows one to guess that the hydraulic behaviour in the two cases is the same one. In the final phase of the flooding, in fact, the vegetation is completely submerged and therefore the motion is mostly developed without interacting with it. In phase A-B the motion happens evidently interacting with the grass, but, however, by observing section A-B we do not find differences regarding the following section; this is justified 
by the fact that also in this case the resistances to the motion applied by the grass are definitely negligible because the speeds with which the water moves in the storage are modest.

\subsection{Configuration 3 (effect of area influence and vegetation presence)}

Also the prototype flooding surface with a bigger area (fig 1b) was covered by synthetic grass (fig. 4), as described in the former paragraph, in order to obtain a configuration which could take into account the combined influence of the surface widening and vegetation presence.

The results of one of the many tests run are shown in fig. 6 . In the filling phase we found a similar behaviour to the one related to configuration 2 tests: the numerical - experimental gap between water level curves is due to the presence of the grass, the draining hydrographs matching is still good. In the draining phase the behaviour is similar to the one related to the previous configurations and, in particular, it is still present the phenomena of "backwater areas" caused by some irregularities linked to the widening of flooding surface and to the presence of grass.

Dealing with the considerations related to the flooding phase which can be read on a water level diagram by applying the points $\mathrm{A}$ and $\mathrm{B}$, what we said in the previous paragraph about configuration 2 is still valid.

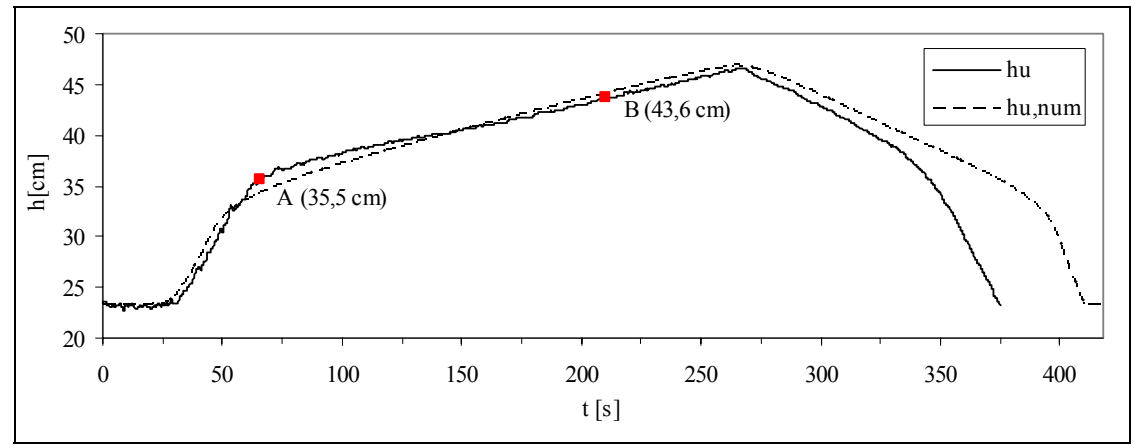

Figure 5: Configuration 2: water levels upstream the floodgate.

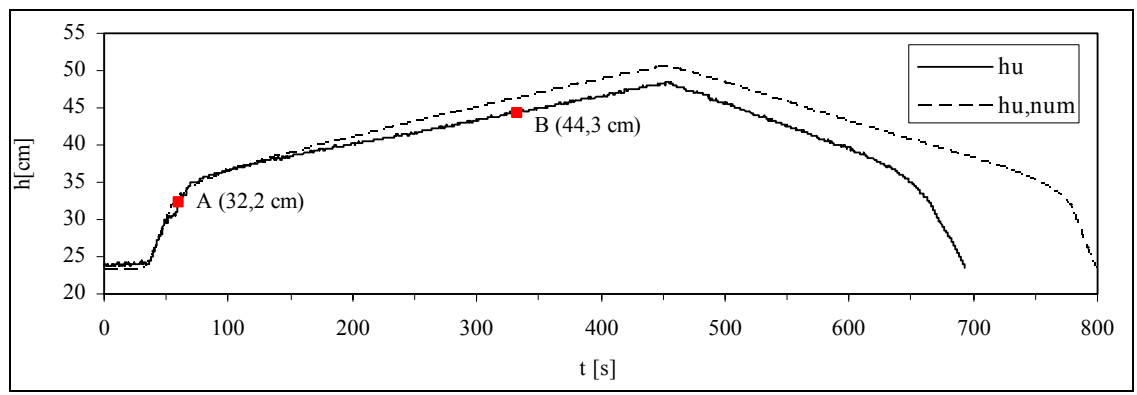

Figure 6: Configuration 3: water levels upstream the floodgate. 


\section{Conclusions}

In a previous paper [15] the result was explained of an experimental research carried out on the physical prototype represented here in fig. 1a. In this paper it was emphasized of the good correspondence between experimental and numerical data obtained by the model based on the hypothesis of uniform storage and considering the flooding surface $S$ of the storage not constant but function of water level $h$ in the storage. The tests run dealt with three further different configurations: the first one in which the flooding surface of the storage is increased (fig.1b) with respect to the previous cases, the second one covered by synthetic grass to simulate the presence of vegetation on the surface of the storage and the last one in which the widening of the area and the presence of grass are concomitant.

In the configuration with widened area and absence of grass the proposed numerical model approximates very well the experimental measures them during the phase of filling, not equally the phase of draining; in this last one, in fact, a marked theoretical-experimental gap is found that is explained by the creation of "backwater areas" in which the water temporary is hold back and then is given back slowly.

In the configuration with small area and grassy covering the gap between the theoretical behaviour (based on the hypothesis of uniform storage) and that effective (experimental measures) is justified by two things: the obstacle created by the presence of the vegetation to the motion of the water and the presence of "backwater areas". The first one justifies the modest mismatch that there is in phase of filling, the second, similar to what said before, is introduced in phase of draining.

In the configuration with widened area and presence of grass, the deductions drawn for the other configurations were confirmed.

In the cases with grass presence it is allowed to conclude that given the low speeds with which the water moves inside the storage, the existing hydraulic resistance to the motion produced by the vegetation is completely negligible: the hydraulic behaviour in the phase of filling in which the water progressively submerges the grass is very similar to what is developed in the case of completely submerged grass.

In a few words, the filling of the storage is simulated by the numerical model with a higher precision rate in the configurations with absence of grass. This means that the numerical method, that considers the flooding surface $S$ variable (stored curve), simulates well the presence of the patchiness in phase of filling; in fact the numerical-experimental correspondence is smaller in the configurations in which the stored curve is not enough to considered also the vegetation presence. In phase of draining, where the presence of or patchiness or vegetation is not contemplated by the stored curve, the numerical-experimental correspondence is lowered because of the macroscopic effect of the "backwater areas".

In conclusion the uniform storage hypothesis, on which the proposed numerical model is based, at least in the experimentations carried out, can be 
used for the dimensioning of the storage since it allows one estimate values of the useful volume of the storage much closer than the effective ones.

\section{References}

[1] Adami, "Casse di espansione fluviali - Aspetti idraulici” Atti del Corso di Aggiornamento del Politecnico di Milano: La difesa idraulica dei territori fortemente antropizzati, Milano, 1997. Editoriale Bios, (1998)

[2] A. O. Akan, "Detention pond sizing for multiple return periods", ASCE J. of Hydr. Engrg., 115 (5), (1989), pp. 650-664

[3] A. O. Akan, "Single outlet detention-pond analysis and design", ASCE J. Irrig. and Drain Engrg., 115 (5), (1990), pp. 527-536

[4] Armanini A.: Principi di idraulica fluviale. BIOS editore - Cosenza, 1999

[5] Armanini A. Righetti M., Flow resistance in compound vegetated channel, ICHE 98 Advances in Hydro-Science and engineering, Cottbus, Berlin, Germany Sept. 1988

[6] Armanini A. Righetti M., Flow resistance in open channel flows with sparsely distributed bushes, Journal of Hydrology, 2002, v. 269, p. 55-64

[7] Armanini A. Righetti M. Grisenti P., Direct measurement of vegetation resistance in prototype scale, Journal of hydraulic research, 2005, v. 43, n. 5, p. $481-487$

[8] H. A. Basha, "Non linear reservoir routing: a particular analytical solution", ASCE J. of Hydr. Engrg., 120 (5), (1994), pp. 624-632

[9] H. A. Basha, "Routing Equations for Detention Reservoirs", ASCE J. of Hydr. Engrg., 121 (12), (1995), pp. 885-888

[10] L. Da Deppo, "Laminazione delle piene con casse di espansione", Tecniche per la difesa dall'inquinamento, Ed. Bios, (1998)

[11] G. De Martino, D. Pianese, F. De Paola, N. Fontana, M. Giugni, "Considerazioni sulla redazione dei piani stralcio per la tutela del territorio dal rischio idrogeologico", La difesa idraulica del territorio, Atti delle giornate di studio, Trieste, 1999

[12] G. De Martino, F. De Paola, N. Fontana, M. Giugni, "Hydraulic design of on stream floodplain storages", New Trends in Water and Environmental Engineering for Safety and Life, Maione, Majone Lehto \& Monti (eds), Balkema, Rotterdam, (2000)

[13] G. De Martino, F. De Paola, N. Fontana, M. Giugni, "Sul dimensionamento di casse di espansione in linea", $28^{\circ}$ Convegno di Idraulica e Costruzioni Idrauliche, Potenza, (2004)

[14] F. De Paola, N. Fontana, "Alcune considerazioni sul dimensionamento idraulico di casse di espansione in linea", L'efficienza e la vulnerabilità delle opere ed infrastrutture fluviali a seguito di eventi idrologici estremi, Attività svolta nell'ambito del PRIN 2000-2002, Castorani e De Martino (eds), (2005)

[15] F. De Paola, N. Fontana, A. Ranucci "Indagine sperimentale per la verifica del comportamento idraulico di casse di espansione in linea", XXX Convegno di Idraulica e Costruzioni Idrauliche, Roma 2006 
[16] V. Ferro, M. Santoro, "Fondamenti teorici e recenti acquisizioni nel settore delle sistemazioni dei bacini idrografici" Università di Palermo Dipartimento di Ingegneria e Tecnologie Agro-Forestali, Dipartimento di Ingegneria Idraulica e Applicazioni Ambientali, (1999)

[17] U. Maione, "Le casse di espansione", Linee guida per la progettazione delle casse di laminazione. Autorità di Bacino del Fiume Arno, (2000)

[18] B. M. McEnroe, "Preliminary sizing of detention reservoirs to reduce peak discharges", ASCE J. Hydr. Engrg., 118(11), (1992), 1540-1549

[19] V. Marone, "Calcolo di massima di un serbatoio di laminazione", L'Energia Elettrica, 9, (1971)

[20] V. Marone, “Calcolo di massima dell'effetto di laminazione di un serbatoio sulle piene", L'Energia Elettrica, 10, (1964)

[21] A. Paoletti, "Resistenze al moto e processi di laminazione nei corsi d'acqua", Atti del Corso di Aggiornamento del Politecnico di Milano: La difesa idraulica del territorio, Milano, 1996. Editoriale Bios, (1997)

[22] D. Pianese e F. Rossi, "Curve di possibilità di laminazione delle piene", L'Energia Elettrica, 2, (1986), pp. 131-149

[23] G. Pulci Doria, P. Gualtieri, R. Catapano, “Experimental observations through LDA of a current with almost rigid submerged vegetation”, IAHR, Venezia, (2007)

[24] E. Paris, Rischio idraulico: interventi per la protezione idraulica del territorio le casse di espansione. International centre for mechanical sciences monografie CISM. Udine, 2004 